UDC 378.141:331

\title{
Methods of assessing the impact of rigidity on the perception of information in the learning process
}

\author{
Bychkovsky V. ${ }^{*}$, Khanchopoulo E. \\ National technical University of Ukraine "Igor Sikorsky Kiev Polytechnic Institute", Kiev, Ukraine \\ Coach Club Group, Kiev, Ukraine
}

Received: $14.08 .2019 \quad$ Accepted: 20.09 .2019

\begin{abstract}
Annotation. The paper considers a methodology that makes it possible to trace the dynamics of perception of information considering the rigidity factor and move from qualitative to quantitative assessments of the impact of rigidity on the success of learning. The situation when due to the rigidity factor the amount of available information differs from the provided one is considered. Based on the equations of information dynamics, the regularity of the change in the amount of information available to a person is considered. Factor of self-limitation, rate constants of change of amount of information are considered. The real speeds necessary for changing the amount of information and their connection with the limiting factors and constants that characterize a person's personality in terms of perception of information are determined. The method of determining the rate constants of change in the amount of information is shown. A model is developed to determine the relationship between predicted and actual rate of change in the amount of information. The method of transition from a long-term perspective model to a short-term forecast model is proposed. Procedures for assessing the effects of rigidity based on the analysis of human characteristics at the initial stage of observation are considered. Based on the current and established values of the rate of change in the amount of information determined by the relative error due to the sophistication. The fixed time, which characterizes rigidity of the person, is determined. The time required to provide a given relative error value is set. The typical relative error values used in the forecasting and measurement process are considered. It is shown that a relative error is a quantitative characteristic of rigidity. The procedure for determining the required volume of sources of correspondent, technical, parametric, predictive, verbal and visual information is shown.
\end{abstract}

Keywords: successful learning, rigidity, available information, limiting factors, forecasting

\section{Методика оцінювання впливу ригідності на сприйняття інформації в процесі навчання}

\author{
Бичковський В. О., Ханчопуло О. В. \\ Національний технічний університет України “Київський політехнічний інститут імені Ігоря Сікорського", \\ Coach Club Group, Київ, Україна
}

\begin{abstract}
Анотація. У роботі розглянуто методику, яка дає можливість простежити динаміку сприйняття інформації 3 урахуванням фактора ригідності та перейти від якісних до кількісних оцінок впливу ригідності на успішність навчання. Розглянуто ситуацію, коли внаслідок фактору ригідності кількість доступної інформації відрізняється від передбаченої. На підставі рівнянь інформаційної динаміки розглянуто закономірність зміни кількості доступної для людини інформації. Враховано фактор самолімітування, константи швидкості зміни кількості інфрормації та співвідношення між потенційно можливими максимальними значеннями кількості інфрормації. Визначено необхідну і реальну швидкості зміни кількості інформації та їх зв'язок з обмежувальними факторами і константами, які характеризують особистість людини з точки зору сприйняття інформації. Показано методику визначення констант швидкості зміни кількості інформації. Складено модель для визначення співвідношення між передбаченою та реальною швидкостями зміни кількості інформації. Запропоновано методику переходу від прогнозної моделі довгострокової перспективи до прогнозної моделі короткострокової перспективи. Розглянуто процедуру оцінювання наслідків ригідності на підставі аналізу характеристик людини на початковому етапі спостережень. На підставі поточного та усталеного значень
\end{abstract}

\footnotetext{
Corresponding Author: Bychkovskyi Vladislav. Tel. +38(050) 163-75-88. E-mail: bychkovskij@gmail.com National Technical University of Ukraine «lgor Sikorsky Kyiv Polytechnic Institute», Vul. Politechnical, 12, 17th building of NTUU «KPI them. Igor Sikorsky», Kyiv, Ukraine, 03056.

Bidnoвідальний автор: Бичковський Владислав Олексійович. Тел. +38(050) 163-75-88. E-mail: bychkovskij@gmail.com Національний технічний університет України «Київський політехнічний інститут імені Ігоря Сікорського», вул. Політехнічна 12, 17-й корпус НТУУ «КПІ ім. Ігоря Сікорського», Київ, Україна, 03056.
} 
швидкості зміни кількості інформації визначено відносну помилку, зумовлену ригідністю. Визначено постійні часу, які характеризують ригідність людини. Встановлено час, необхідний для забезпечення заданого значення відносної помилки. Прийнято до уваги типові значення відносної помилки, які застосовують в процесі прогнозування та вимірювання. Показано, що відносна помилка $є$ кількісною ознакою ригідності. Розглянуто процедуру щодо визначення необхідного обсягу джерел кореспондентської, технічної, параметричної, випереджувальної, словесної та візуальної інформації.

Ключові слова: успішність навчання, ригідність, доступна інформація, обмежувальні фрактори, прогнозування

\title{
Методика оценивания влияния ригидности на восприятие информации в процессе обучения
}

\author{
Бычковский В. А., Ханчопуло Е. В.
}

Национальный технический университет Украины «Киевский политехнический институт имени Игоря Сикорского», Киев, Украина

Coach Club Group, Киев, Украина

\begin{abstract}
Аннотация. В работе рассмотрена методика, которая дает возможность проследить динамику восприятия информации с учетом фактора ригидности и перейти от качественных к количественным оценкам влияния ригидности на успешность обучения. Рассмотрена ситуация, когда вследствие фактора ригидности количество доступной информации отличается от предусмотренной. На основе уравнений информационной динамики рассмотрены закономерности изменения количества доступной для человека информации. Учтен фрактор самолимитирования, константы скорости изменения количества информации и соотношение между потенциально возможными максимальными значениями количества информации. Определены необходимая и реальная скорости изменения количества информации и их взаимосвязь с ограничивающими факторами и константами, которые характеризуют личность человека с точки зрения восприятия информации. Показана методика определения констант скорости изменения количества информации. Составлена модель для определения соотношения между предусмотренной и реальной скоростями изменения количества информации. Предложена методика перехода от прогнозной модели долгосрочной перспективы к прогнозной модели краткосрочной перспективы. Рассмотрена процедура оценивания последствий ригидности на основе анализа характеристик человека на начальном этапе наблюдения. На основе текущего и установившегося значений скорости изменения количества информации определена относительная ошибка, обусловленная ригидностью. Определены постоянные времени, которые характеризуют ригидность человека. Установлено время, необходимое для обеспечения заданного значения относительной ошибки. Приняты во внимание типовые значения относительной ошибки, которые используются в процессе прогнозирования и измерения. Показано, что относительная ошибка есть количественным показателем ригидности. Рассмотрена процедура определения необходимого количества источников корреспондентской, технической, параметрической, опережающей, словесной и визуальной информации.
\end{abstract}

Ключевые слова: успешность обучения, ригидность, доступная информация, ограничительные факторы, прогнозирование.

\section{Bcmyn}

Сучасні інформаційні технології базуються на застосуванні інформаційних наук для вирішення широкого кола різноманітних задач, у тому числі і в освіті. Інформатизація освіти відповідно до Національної доктрини ї̈ розвитку у XXI столітті передбачає перенесення уваги із процесу навчання на його кінцевий результат [1]. Прогнозувати результативність навчання представляється можливим на підставі аналізу динамічних моделей та ретельного дослідження процесів, які відбуваються в оточуючому середовищі та впливають на людину $[2,3]$. До базових властивостей особистості людини відносяться ригідність та креативність. Ригідність перешкоджає установленню психічного гомеостазу в разі зміни зовнішньої ситуації внаслідок фіксації неефективних стратегій поведінки та впливає на успішність навчання [4]. Для об'єктивної оцінки рівня ригідності необхідно використовувати методи, які дають можливість оперувати не стільки якісними, скільки кількісними показниками людини. Одним із варіантів вирішення поставленої задачі є логічний аналіз методом аналогій з електричними колами [5].

Передбачається ідентифрікація інформаційних параметрів особистості, що навчається, на підставі визначення ригідності (аналогу індуктивності) та часу запізнювання (аналогу опору). Утворене інформаційне коло характеризує процес інформаційної взаємодії того, хто навчає, з тим, хто навчається. Аналіз, як такий, проводиться у частотній області, що не дає можливості прогнозувати наслідки ригідності. Для складання прогнозних моделей необхідно перейти у часову область $[6,7]$. 
Питанню ригідності присвячена велика кількість досліджень, в яких проблема розглядається 3 різних точок зору. Ригідність має суттєве значення як фактор недостатньої успішності та у пізнавальному процесі $[8,9]$. Оцінювання рівня ригідності базується на відомих технологіях $[10,11]$.

Що стосується урахування впливу ригідності на динаміку інформаційних процесів, то за умови застосування розповсюджених методик вона залишається прихованою. Таким чином, не представляється можливим оцінювати вплив фактора часу на успішність навчання. Необхідно зауважити , що оцінювання впливу ригідності на динаміку інформаційних процесів дасть можливість забезпечити кількісний аналіз характеристик людини-оператора $[12,13]$.

В процесі тестування та відбору персоналу стане можливим використовувати прогнозні моделі щодо подальшого навчання та підвищення професійного рівня фахівців [14, 15]. Таким чином, з'ясування впливу ригідності на сприйняття інформації з метою визначення реальних та потенційних можливостей людини у процесі навчання необхідно розглядати як актуальну задачу.

\section{II Матеріал і методи дослідження}

Розглянемо ситуацію, коли необхідні кількість інформації $I_{1}=I_{1}(t)$, яка повинна бути доступною для людини, протягом часу збільшується та асимптотично наближується до свого потенційно можливого максимального значення $I_{1 m}$.

Якщо $K_{1}$ - константа швидкості зміни $I_{1}$, то можна записати:

$$
d I_{1}=K_{1}\left(I_{1 m}-I_{1}\right) d t .
$$

Внаслідок ригідності людини реальна кількість доступної інформації:

$$
d I_{2}=K_{2}\left(I_{2 m}-I_{2}\right) d t
$$

де $K_{2}<K_{1}, \quad I_{2 m}<I_{1 m}$.

На підставі рівнянь (1), (2) запишемо:

$$
\begin{aligned}
& \frac{d I_{1}}{d t}+K_{1} I_{1}=K_{1} I_{1 m} \\
& \frac{d I_{2}}{d t}+K_{2} I_{2}=K_{2} I_{2 m} .
\end{aligned}
$$

За нульових початкових умов розв'язок рівнянь (3), (4) має наступний вигляд:

$$
\begin{aligned}
& I_{1}=I_{1 m}\left[1-\exp \left(-K_{1} t\right),\right. \\
& I_{2}=I_{2 m}\left[1-\exp \left(-K_{2} t\right)\right] .
\end{aligned}
$$

Приймаємо до уваги, що швидкості зміни кількості інформації

$$
C_{1}=d I_{1} / d t, C_{2}=d I_{2} / d t \text {. }
$$

Тоді на підставі залежностей (5), (6) знаходимо:

$$
\begin{aligned}
& C_{1}=K_{1} I_{1 m} \exp \left(-K_{1} t\right), \\
& C_{2}=K_{2} I_{2 m} \exp \left(-K_{2} t\right) .
\end{aligned}
$$

Визначимо нахил дотичних, проведених в точці $t=0$ до кривих (5), (6):

$$
\begin{aligned}
& \left.\frac{d I_{1}}{d t}\right|_{t=0}=K_{1} I_{1 m} \\
& \left.\frac{d I_{2}}{d t}\right|_{t=0}=K_{2} I_{2 m} .
\end{aligned}
$$


Аналіз залежностей (9), (10) показує, що $K_{1}=1 / t_{1}, K_{2}=1 / t_{2}$. Час $t_{1}$ відповідає моменту перетину дотичної до кривої (5) з рівнем $I_{1 m}$. Час $t_{2}$ відповідає моменту перетину дотичної до кривої (6) з рівнем $I_{1 m}$. Дотичну проведено в точці $t=0$. Перейдемо від оригіналів $(7),(8)$ до їх зображень по Лапласу:

$$
\begin{aligned}
& C_{1}^{*}(p)=\frac{K_{1} I_{1 m}}{p+K_{1}}, \\
& C_{2}^{*}(p)=\frac{K_{2} I_{2 m}}{p+K_{2}} .
\end{aligned}
$$

На підставі рівнянь (11), (12) визначаємо передаточну фрункцію ланки, яка описує ригідні властивості особи, що навчається: $W(p)=C^{*}{ }_{2}(p) / C_{1}^{*}(p)$. Таким чином:

$$
W(p)=\frac{K_{2} I_{2 m}\left(p+K_{1}\right)}{K_{1} I_{1 m}\left(p+K_{2}\right)} .
$$

Введемо у розгляд постійні часу,

$$
T_{1}=1 / K_{1}, T_{2}=1 / K_{2} .
$$

Тоді залежність (13) можна записати у вигляді

$$
W(p)=\frac{I_{2 m}\left(T_{1} p+1\right)}{I_{1 m}\left(T_{2} p+1\right)} .
$$

На підставі передаточної функції (14) можна визначити реакцію ланки на вхідні впливи різноманітного характеру. 3 іншого боку, необхідно прийняти до уваги, що рівняння (5), (6) відносяться до прогнозних моделей довгострокової перспективи. Слід вважати доцільним перейти до моделей короткострокової перспективи, які з врахуванням співвідношень (5), (6) дадуть можливість простежити наслідки інформаційної ригідності на підставі спостережень за характеристиками на початковому етапі. Така можливість існує, оскільки на підставі аналізу залежності (5) можна записати умову (9).

Якщо позначити $C_{11}=K_{1} I_{1 m}$, то на початковому етапі спостережень $I_{1}=C_{11} t$. До аналогічного результату можна прийти також, якщо розкласти у формулі (5) експоненціальну функцію в ряд, обмежитися двома першими членами ряду та визначити похідну $d I_{1} / d t$. Отже, сенс проведених досліджень - отримати дані щодо помилки на початковому етапі спостережень враховуючи асимптотику довгострокової прогнозної функції.

\section{III Результати}

У ситуації, яка розглядається, $I_{1}=C_{11} t$, де $C_{11}=K_{1} I_{1 m}$. Таким чином, розглядається типова прогнозна модель, коли кількість інформації збільшується згідно лінійного закону [7]. Тоді визначаємо $d I_{1} / d t=C_{11}$, а відповідне зображення по Лапласу $C_{11}^{*}(p)=C_{11} / p$. Оскільки $C_{2}^{*}(p)=C_{1}^{*}(p) W(p)$, то на підставі залежності (14) знаходимо,

$$
C_{2}^{*}(p)=\frac{I_{2 m} C_{11}\left(T_{1} p+1\right)}{p I_{1 m}\left(T_{2} p+1\right)}
$$

Перепишемо рівняння (15) у вигляді:

$$
C_{2}^{*}(p)=\frac{I_{2 m} C_{11} T_{1}}{I_{1 m}\left(T_{2} p+1\right)}+\frac{I_{2 m} C_{11}}{p I_{1 m}\left(T_{2} p+1\right)} .
$$

Переходимо від зображення (16) до оригіналу:

$$
C_{2}=\frac{I_{2 m} C_{11} T_{1}}{I_{1 m} T_{2}} \exp \left(-\frac{t}{T_{2}}\right)+\frac{I_{2 m} C_{11}}{I_{1 m}}\left[1-\exp \left(-\frac{t}{T_{2}}\right)\right] .
$$

На підставі залежності (17) знаходимо усталене значення: 


$$
C_{2 \mathrm{cT}}=\lim _{t \rightarrow \infty} C_{2}(t)=\frac{I_{2 m} C_{11}}{I_{1 m}} .
$$

Відносна помилка у сприйнятті інформації, викликана ригідністю:

$$
\gamma=\frac{C_{2 \mathrm{ct}}-C_{2}}{C_{2 \mathrm{cT}}} .
$$

Враховуючи залежності (17), (18), (19), визначаємо:

$$
\gamma=\left(1-\frac{T_{1}}{T_{2}}\right) \exp \left(-\frac{t}{T_{2}}\right) .
$$

Зауважимо, що $T_{1}<T_{2}$, оскільки $K_{1}>K_{2}$. На підставі формули (20) знаходимо час, необхідний для забезпечення заданого значення відносної помилки, викликаної ригідністю:

$$
t=T_{2} \ln \frac{T_{2}-T_{1}}{\gamma T_{2}} .
$$

Виходячи із залежності (21) можна визначити обмеження на відносну помилку:

$$
\gamma<1-\frac{T_{1}}{T_{2}}
$$

Таким чином, існує можливість простежити динаміку інформаційних процесів та визначити передаточну функцію ланки, яка описує ригідні властивості людини, встановити швидкості зміни кількості інформації та їх усталені значення. На підставі оцінювання відносної помилки у сприйнятті інформації встановлюється необхідний час тестування та обмеження на відносну помилку.

\section{IV Обговорення}

Приймаючи до уваги залежність (20), запишемо,

$$
\gamma=\left(1-\frac{T_{1}}{T_{2}}\right) \exp \left(-\frac{T_{1}}{T_{2}} \cdot \frac{t}{T_{1}}\right) .
$$

На підставі співвідношення (22) можна визначити закономірність зменшення відносної помилки протягом часу (рис. 1).

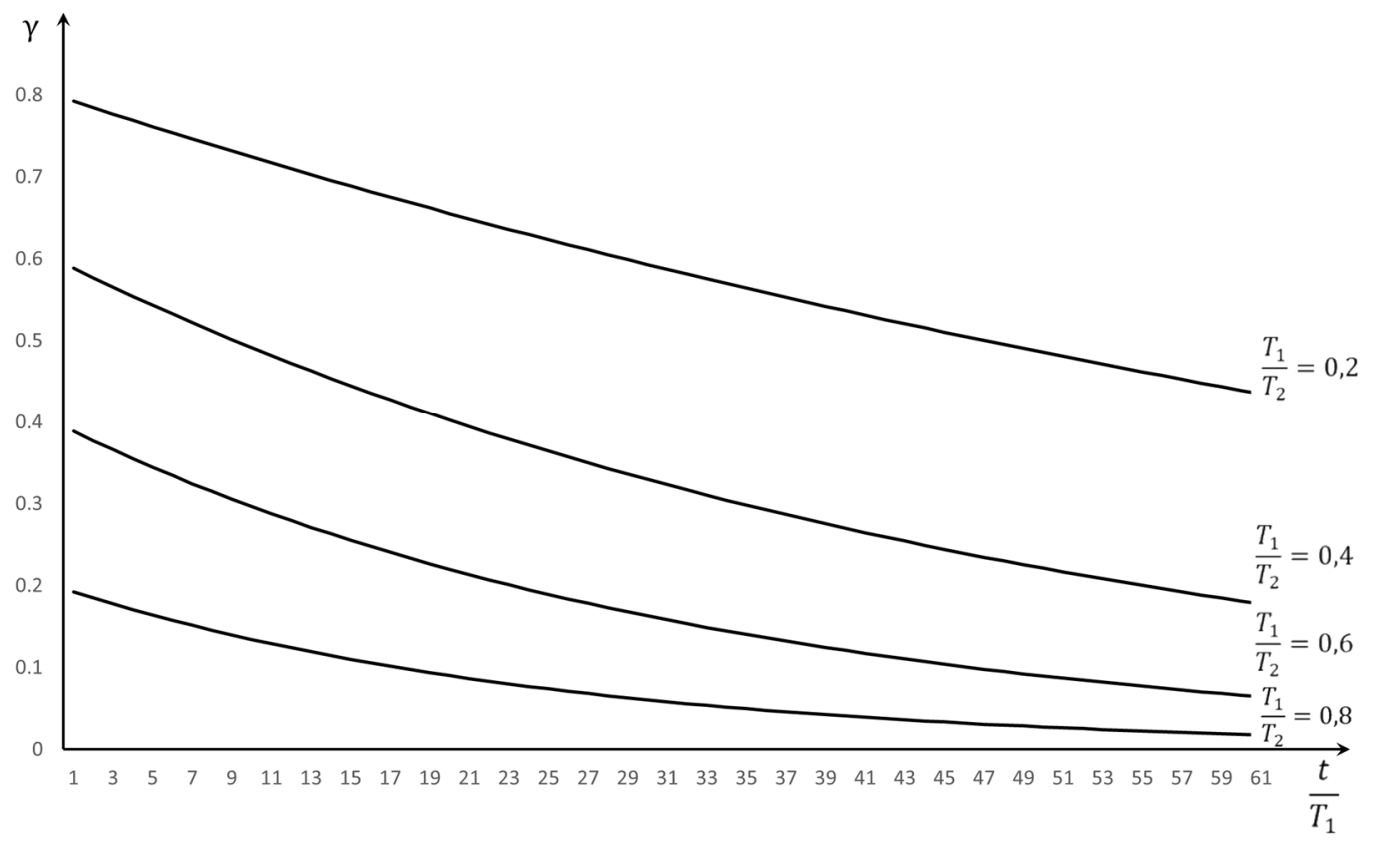

Рис. 1. Закономірність зменшення відносної помилки 
Аналіз отриманих закономірностей показує, що із збільшенням ригідності (зменшенням відношення $T_{1} / T_{2}$ відносна помилка збільшується. Таким чином, отримано дані щодо відносної помилки на початковому етапі спостережень враховуючи асимптотику довгострокової прогнозної функції. Приймемо до уваги, що в задачах прогнозування та вимірювань часто розглядають порогову величину $\gamma=0,5$ [7]. Це дає можливість визначити час $t_{0,5}$, через який відносна помилка досягає значення $\gamma=0,5$. За даної умови на підставі залежності (21) визначаємо:

$$
t_{0,5}=T_{2} \ln \left[2\left(1-\frac{T_{1}}{T_{2}}\right)\right] .
$$

Аналіз залежності (23) показує, що відношення T0,5/T2 знаходиться в межах від 0,693 до 0 за умови, що відношення $T_{1} / T_{2}$ змінюється від 0 до 0,5. Отже, отримані результати дають можливість оцінити відносну помилку як кількісну ознаку ригідності та визначити час, через який відносна помилка досягає значення $\gamma=0,5$.

Необхідно прийняти до уваги, що часовий показник може пов'язуватися і з іншими значеннями $\gamma$, які $€$ меншими за $\gamma=0,5$. Тоді доцільно визначити необхідну кількість джерел інформації $V m i n$, яка забезпечує відносну помилку $\gamma$. Згідно закону великих чисел П. Л. Чебишева $V_{\min }=4 b / \gamma$, де $b$ знаходиться в межах від 5 до 7 [7]. Якщо прийняти до уваги залежність (22), то можна визначити необхідний темп використання джерел кореспондентської, випереджувальної, словесної та візуальної інформації. 3 іншого боку, в разі певних обмежень на допустимий час роботи з джерелами інформації $i$ того виду, можна скористатися показником

$$
\Gamma_{i}=\frac{\gamma_{\text {imax }}-\gamma_{i}}{\gamma_{\text {imax }}}
$$

де $\gamma_{i}$ - відносна помилка для $i$-того виду інформації; $\gamma_{\text {imax }}$ - максимально можливе допустиме значення $\gamma_{i}$. На підставі залежності (24) можна скласти ідеальну та реальну карти компетенцій та доповнити відомі процедури оцінювання персоналу $[16,17,18]$. Тоді з'являється можливість удосконалити існуючі технології оцінювання професійних можливостей студентів $[19,20]$.

\section{V Висновки}

Отримані результати показують, що оцінити ригідні властивості людини, яка навчається, можна на підставі прогнозних моделей для необхідної та реальної закономірностей зміни кількості доступної інформації. Щоб визначитися із швидкостями зміни кількості інформації, необхідно встановити константи $K_{1}, K_{2}$, які знаходяться на підставі аналізу моментів претину дотичних до кривих $I_{1}(t)$ та $I_{2}(t)$ в точці початку спостережень $t=0$ з потенційно можливими максимальними значеннями кількості інформації. Результати тестування повинні базуватися на випробувальному впливі з постійною швидкістю надходження інформації та подальшим визначенням відносної помилки сприйняття інформації. Результати досліджень можуть застосовуватися в процесі навчання, психодіагностики та кадрового відбору персоналу $[14,15]$. Вони доповнюють відомі дані щодо впливу ригідності на сприйняття інфрормації та успішність навчання.

\section{Бібліографічні посилання}

1. Арбузов Ю. В., Ахромушкин Е. А., Беляков А. В., Глаголев В. Б., Грушо А. А., Гусева Т. И., Заботнев М. С., Евсеев А. И., Конин А. Л., Крепков И. М., Кузнецов Ю. М., Кулагин В. П., Линьков В. М., Липай Б. Р., Маслов С. И., Очков В. Ф., Савкин А. Н., Седов А. Н., Семенов А. Ю., Симонов А. Н., Скворцова Т. М., Станкевич И. В., Сутченков А. А., Тихонов А. И., Федоров М. Б. Информатизация образования: направления, средства, технологи: пособие. Москва : МЭИ, 2004. 864 с.

2. Мелик-Гайказян И. В. Информационные процессы и реальность. Москва : Наука, 1998. 192 с.

3. Сергеев С. Ф. Инструменты обучающей среды: интеллект и когнитивные стили / Образовательные технологии. 2010. №4. C. 28-39.

4. Смирнова С.В., Павлова Е.В. Соотношение ригидности и креативности у студентов-первокурсников вуза / Сибирский педагогический журнал. 2002. Вып. 16-17. С. 127-128.

5. Жабреев В. С., Акулова Т.Н. Способ определения информационных параметров обучаемого или тестируемого человека / Патент на изобретение №2360595.10.07.2009. 9 с. 
6. Петров В. М. Социальная и культурная динамика. Быстротекущие процессы. Информационный подход. Москва: Ленанд, 2016. 336 с.

7. Кузнєцов Ю. М., Скляров Р. А. Прогнозування розвитку технічних систем. Киев : ТОВ «ЗМОК»-ПП «ГНОЗИС», 2004. $323 \mathrm{c.}$.

8. Яшин А. А. Когнитивная ригидность как фрактор недостаточной успешности / Психология и психотехника. 2015. Вып. 11. С. 1146-1157.

9. Гордыня Н.Д. Исследование ригидности-гибкости познавательного контроля и импульсивности-ресрлексивности у студентов-авиадиспечеров / Молодой ученый. 2013. Вып. 5. С. 634-638.

10. ЗалевскийГ.В., Богомаз С. А. Специализация полушарий мозга человека как фактор, детерминирующий его ригидность / Сибирский психологический журнал. 1998. Вып. 10. С. 36-41.

11. Залевский Г. В. Томский опросник ригидности Г. В. Залевского / Сибирский психологический журнал. 2000. Вып. 12. C. 129-134.

12. Ємченко І. В. Методи і технічні засоби митного контролю. Київ : Центр учбової літератури, 2007. 432 с.

13. Стенін О. А., Михальов О.І., Мелкумян К. Ю. Автоматичне навчання операторів ергатичних систем. Київ : НТуУ «КП।», 2013. $180 \mathrm{C}$.

14. Вулкович-Стадник А. А. Оценка персонала: четкий алгоритм действий и качественные практические решения. Москва : Эксмо, 2008. 192 с.

15. Иванова С. В. Кандидат, новичок, сотрудник. Инструменты управления персоналом, которые реально работают на практике. Москва : Эксмо, 2008. 304 с.

16. Киселева М. Н. Оценка персонала. Санкт-Петербург : Питер, 2015. 173 с.

17. Bienzeisler B. Die Competence Card als Mess- und Steuerungsinstrument für die Dienstleistungswirtschaft. Praxishandbuch Controlling. 2005. PP. 167-183. doi: https://doi.org/10.1007/978-3-322-90505-5_6.

18. Бурлачук Л. Ф., Володина Н. П. Оценка персонала: проблема выбора инструментов / ЭКО. 2003. №11. С. 89-104.

19. Aggarwal A., Thakur G. S. M. Techniques of Performance Appraisal-A Review / International Journal of Engineering and Advanced Technology (IJEAT). 2013. Volume 2. Issue 3. PP. 617-621.

20. Baughman J. A., Brumm Th. J., Mickelson S. K. Student Professional Development: Competency-Based Learning and Assessment / The Journal of Technology Studies. 2012. Vol. 38. No. 2. PP. 115-127.

\section{References}

1. Arbuzov, Ju.V., Ahromushkin, E.A., Beljakov, A.V., Glagolev, V.B., Grusho, A.A., Guseva, T.I., Zabotnev, M.S., Evseev, A.I., Konin, A.L., Krepkov, I.M., Kuznecov, Ju.M., Kulagin, V.P., Lin'kov, V.M., Lipaj, B.R., Maslov, S.I., Ochkov, V.F., Savkin, A.N., Sedov, A.N., Semenov, A.Ju., Simonov, A.N., Skvorcova, T.M., Stankevich, I.V., Sutchenkov, A.A., Tihonov, A.I., Fedorov, M.B. (2004). Informatizacija obrazovanija: napravlenija, sredstva, tehnologi: posobie [Informatization of education: directions, means, technologists: aid]. MJel, Moskow, Russia. [ in Russian ]

2. Melnik-Gajkazyan, I.V. (1998). Informazionnie prozessi I realnost [Information Processes and Reality]. Nauka, Moscow, Russia. [in Russian]

3. Sergeev, S.F. (2010). Instrumenty obuchayushhej sredy: intellekt i kognitivnye stili. Obrazovatelnye texnologii, 4, 28-39. [in Russian].

4. Smirnova, S.V., Pavlova, E.V. (2002). Sootnoshenie rigidnosti i kreativnosti u studentov-pervokursnikov vuza [The ratio of rigidity and creativity in first-year students]. The Siberian Pedagogical Journal, 16-17, 127-128. [in Russian]

5. Zhabreev, V.S., Akulova, T.N. (2009). Sposob opredelenija informacionnyh parametrov obuchaemogo ili testiruemogo cheloveka [The method of determining the information parameters of a trained or tested person]. Invention patent № 2360595, publication date 10.07.2009. [in Russian]

6. Petrov, V.M. (2016). Socialnaya i kulturnaya dinamika. bystrotekushhie processy. Informacionnyj podxod. Lenand, Moscow, Russia. [in Russian]

7. Kuznietsov, Yu.M., Sklyarov, R.A. (2004). Prohnozuvannia rozvytku tekhnichnykh system [Forecasting the development of technical systems]. TOV «ZMOK»-PP «HNOZYS», Kyiv, Ukraine. [in Ukrainian]

8. Yashin, A.A. (2015). Cognitive Rigidity as the Factor of Poor Success. Psychology and Psychotechnics, 11, 1146-1157. doi: 10.7256/2070-8955.2015.11.16968 [in Russian]

9. Gordynja, N.D. (2013). Issledovanie rigidnosti-gibkosti poznavatel'nogo kontrolja i impul'sivnosti-refleksivnosti u studentovaviadispecherov [The study of rigidity-flexibility of cognitive control and impulsivity-reflexivity in students of air traffic controllers]. Young scientist, 5(52), t. 3, 634-638. [in Russian]

10. Zalevskij, G.V., Bogomaz, S.A. (1998). Specializaciya polusharij mozga cheloveka kak faktor, determiniruyushchij ego rigidnost' [Specialization of the human brain hemispheres as a factor determining its rigidity]. Siberian Journal of Psychology, 10, 36-41. [in Russian]

11. Zalevskij, G.V. (2000). Tomskij oprosnik rigidnosti. G. V. Zalevskogo [Tomsk rigidity questionnaire of G.V. Zalevsky]. Siberian Journal of Psychology, 12, 129-134. [in Russian]

12. Yemchenko, I.V. (2007). Metody i tekhnichni zasoby mytnoho kontroliu [Methods and technology to control monitoring]. Tsentr uchbovoi literatury, Kyiv, Ukraine. [in Ukrainian]

13. Stenin, O.A., Mykhalov, O.l., Melkumian, K.Yu. (2013). Avtomatychne navchannia operatoriv erhatychnykh system [Automatically learning of ergatic systems operators]. NTUU «KPI», Kyiv, Ukraine. [in Ukrainian] 
14. Vulkovich-Stadnik, A.A. (2008). Ocenka personala: chetkij algoritm dejstvij i kachestvennye prakticheskie resheniya [Personnel assessment: a clear algorithm of actions and high-quality practical solutions]. Eksmo, Moscow, Russia. [in Russian]

15. Ivanova, S.V. (2008). Kandidat, novichok, sotrudnik. Instrumenty upravleniya personalom, kotorye real'no rabotayut na praktike [Candidate, beginner, employee. HR tools that really work in practice]. Eksmo, Moscow, Russia, 304. [in Russian]

16. Kiseleva, M.N. (2015). Ocenka personala. Piter, Sankt-Peterburg, Russia. [in Russian]

17. Bienzeisler, B. (2005). Die Competence Card als Mess- und Steuerungsinstrument für die Dienstleistungswirtschaft. Praxishandbuch Controlling, 167-183. doi: https://doi.org/10.1007/978-3-322-90505-5_6

18. Burlachuk, I.F., Volodina, N.P. (2003). Ocenka personala: problema vybora instrumentov. Eko, 11, 89-104.

19. Aggarwal, A., Thakur, G.S.M. (2013). Techniques of Performance Appraisal-A Review. International Journal of Engineering and Advanced Technology (IJEAT), 2(3), 617-621.

20. Baughman, J.A., Brumm, Th.J., Mickelson, S.K. (2012). Student Professional Development: Competency-Based Learning and Assessment. The Journal of Technology Studies, 38(2), 115-127.

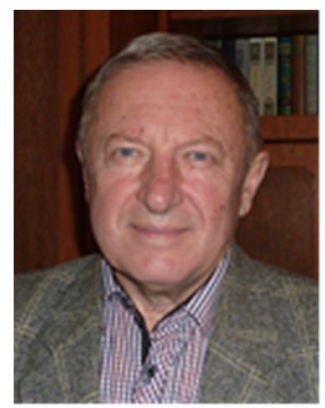

Бичковський Владислав Олексійович.

К.техн.н., доцент, доцент кафедри радіотехнічних пристроїв та систем, Національний технічний університет України «Київський політехнічний інститут імені Ігоря Сікорського»,

вул. Політехнічна 12, 17-й корпус НТУУ «КПІ ім. Ігоря Сікорського», Київ, Україна, 03056.

Тел. +38(050) 163-75-88. E-mail: bychkovskij.vlad@gmail.com

\section{Bychkovskyi Vladyslav Oleksiyovych,}

Cand.Sc. (Eng.), Associate Professor, Associate Professor of Radiotechnical Devices and Systems

Department, National Technical University of Ukraine «lgor Sikorsky Kyiv Polytechnic Institute»

Vul. Politechnical, 12, 17th building of NTUU «KPI them. Igor Sikorsky», Kyiv, Ukraine, 03056.

Tel. +38(050) 163-75-88. E-mail: bychkovskij.vlad@gmail.com

ORCID: 0000-0003-1065-4924

Researcher ID: I-4729-2018

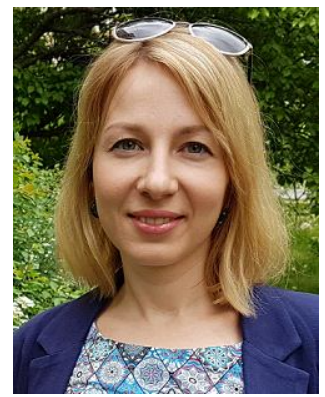

\section{Ханчопуло Олена Владиславівна}

ICU коуч, HR-директор, Coach Club Group,

Киев, Україна.

Тел. +38(096)303-93-39. E-mail: khanchopoulo@gmail.com

\section{Khanchopoulo Olena Vladislavivna,}

ICU coach, HR-director, Coach Club Group,

Kyiv, Ukraine.

Tel. +38(096) 303-93-39. E-mail: khanchopoulo@gmail.com

\section{Citation (APA):}

Bychkovsky, V., Khanchopoulo, E. (2019). Methods of assessing the impact of rigidity on the perception of information in the learning process. Engineering and Educational Technologies, 7 (3), 21-28. doi: https://doi.org/10.30929/2307-9770.2019.07.03.02

\section{Цитування (ДСТУ 8302:2015):}

Бичковський В. О., Ханчопуло О. В. Методика оцінювання впливу ригідності на сприйняття інформації в процесі навчання / Інженерні та освітні технології. 2019. Т. 7. № 3. С. 21-28. doi: https://doi.org/10.30929/2307-9770.2019.07.03.02

Обсяг cmammi: сторінок - 8 ; умовних друк. аркушів - 1,159. 